University of Nebraska - Lincoln

DigitalCommons@University of Nebraska - Lincoln

U.S. National Park Service Publications and

Papers

National Park Service

2017

\title{
Large-scale movement behavior in a reintroduced predator population
}

Frances E. Buderman

Colorado State University, franny.buderman@colostate.edu

Melvin B. Hooten

U.S. Geological Survey, Mevin.Hooten@colostate.edu

Jacob S. Ivan

Colorado Parks and Wildlife

Tanya M. Shenk

University of Nebraska-Lincoln, tshenk2@unl.edu

Follow this and additional works at: https://digitalcommons.unl.edu/natlpark

Buderman, Frances E.; Hooten, Melvin B.; Ivan, Jacob S.; and Shenk, Tanya M., "Large-scale movement behavior in a reintroduced predator population" (2017). U.S. National Park Service Publications and Papers. 144.

https://digitalcommons.unl.edu/natlpark/144

This Article is brought to you for free and open access by the National Park Service at DigitalCommons@University of Nebraska - Lincoln. It has been accepted for inclusion in U.S. National Park Service Publications and Papers by an authorized administrator of DigitalCommons@University of Nebraska - Lincoln. 


\title{
Large-scale movement behavior in a reintroduced predator population
}

\author{
Frances E. Buderman, Mevin B. Hooten, Jacob S. Ivan and Tanya M. Shenk \\ F. E. Buderman (http://orcid.org/0000-0001-9778-9906) (franny.buderman@colostate.edu) Dept of Fish, Wildlife, and Conservation Biology, \\ Colorado State Univ., Fort Collins, CO, USA. - M. B. Hooten, U.S. Geological Survey, Colorado Cooperative Fish and Wildlife Research Unit, \\ Dept of Fish, Wildlife, and Conservation Biology and Statistics, Colorado State Univ., Fort Collins, CO, USA, and Graduate Degree Program in \\ Ecology, Colorado State Univ., Fort Collins, CO, USA. - J. S. Ivan, Colorado Parks and Wildlife, Fort Collins, CO, USA. - T. M. Shenk, \\ National Park Service, Great Plains Cooperative Ecosystem Studies Unit, Univ. of Nebraska, Lincoln, NE, USA.
}

\begin{abstract}
Understanding movement behavior and identifying areas of landscape connectivity is critical for the conservation of many species. However, collecting fine-scale movement data can be prohibitively time consuming and costly, especially for rare or endangered species, whereas existing data sets may provide the best available information on animal movement. Contemporary movement models may not be an option for modeling existing data due to low temporal resolution and large or unusual error structures, but inference can still be obtained using a functional movement modeling approach. We use a functional movement model to perform a population-level analysis of telemetry data collected during the reintroduction of Canada lynx to Colorado. Little is known about southern lynx populations compared to those in Canada and Alaska, and inference is often limited to a few individuals due to their low densities. Our analysis of a population of Canada lynx fills significant gaps in the knowledge of Canada lynx behavior at the southern edge of its historical range. We analyzed functions of individual-level movement paths, such as speed, residence time, and tortuosity, and identified a region of connectivity that extended north from the San Juan Mountains, along the continental divide, and terminated in Wyoming at the northern edge of the Southern Rocky Mountains. Individuals were able to traverse large distances across non-boreal habitat, including exploratory movements to the Greater Yellowstone area and beyond. We found evidence for an effect of seasonality and breeding status on many of the movement quantities and documented a potential reintroduction effect. Our findings provide the first analysis of Canada lynx movement in Colorado and substantially augment the information available for conservation and management decisions. The functional movement framework can be extended to other species and demonstrates that information on movement behavior can be obtained using existing data sets.
\end{abstract}

Functional connectivity, the degree to which the landscape facilitates or impedes movement among resource patches (Taylor et al. 1993), is of critical importance for a number of ecological processes, such as gene flow (Coulon et al. 2004, Keyghobadi et al. 2005), metapopulation dynamics (Hanski 1999), migration (Sawyer et al. 2005), and range expansion (Safranyik et al. 2010). Given the importance of connectivity for wildlife population persistence, its preservation and restoration have become conservation priorities. Many methods exist for identifying areas of high connectivity, but few of these methods are capable of quantifying realized functional connectivity of the landscape (Calabrese and Fagan 2004). Whereas structural connectivity focuses on the spatial arrangement of the landscape in isolation of animal behavior, functional connectivity incorporates the behavior of the individual (Crooks and Sanjayan 2006), either through knowledge about their physiology and dispersal capabilities (structural functional connectivity) or by observing individuals moving through a landscape (realized functional connectivity; Calabrese and Fagan 2004). The movement path of an individual arises from sequential decisions regarding their needs and perceptions of the surrounding habitat, and it is these decisions that ultimately give rise to the functional connectivity of the landscape (Tracey 2006).

Despite the priority on maintaining and increasing connectivity, few methods for evaluating connectivity explicitly incorporate animal movement (but see Tracey 2006, Tracey et al. 2013). Realized functional connectivity can be difficult and labor intensive to measure because it requires long-term monitoring of individual movements (Ferrari et al. 2007). However, the locations of individuals are often collected in conjunction with other monitoring data; existing data sets may contain a wealth of spatial information but were not explicitly collected to monitor movement across the landscape. Utilizing existing data on animal movement, despite its potential deficiencies, may provide the best available information for landscape-level management decisions intended to improve connectivity.

Connectivity planning, particularly the delineation and maintenance of corridors, is often associated with high costs 
and risks (Morrison and Reynolds 2006). In an ideal scenario, connectivity planning would allow for data collection to explicitly identify optimal management decisions, such as corridor placement. Logistically, however, there are often time or budget constraints that preclude collecting data explicitly for the decision under consideration (Clevenger et al. 2002). In addition, basic species-specific information, such as habitat requirements, movement abilities, movement behaviors (e.g. seasonality, age, and sex differences in movement), and facilitators or impediments to movement, is critical for informing management decisions, but is often lacking during the decision making process (Bennett 1999). Given the costly and political nature of connectivity planning, existing data sets on animal movement may provide the best available information at a time when a decision needs to be made, particularly for rare or endangered species at low densities. However, novel methods may be necessary to deal with unique factors of existing data, such as irregular time intervals, missing data, and multiple data types.

We extended the approach presented by Buderman et al. (2016) to simultaneously model the movement paths of a population of individual animals using data that were not collected with the intention of modeling animal movement, but that contain valuable spatial information. The functional movement modeling approach is flexible and can be modified to account for other types of measurement error beyond the combination of Argos (a polar-orbiting satellite system) and radio-telemetry data presented here. We used the modeled movement paths to identify temporal and demographic patterns in movement behavior across a threatened population of reintroduced Canada lynx Lynx canadensis. Spatial patterns in movement behavior were used to identify areas that suggest high landscape connectivity. We obtained inference for movement behavior using derived quantities that can be modified to fit the species and system in question and are not constrained to those presented here.

\section{Reintroduced Canada Lynx in Colorado}

Canada lynx were designated as an endangered species in Colorado in 1973, although the last verified Canada lynx record occurred in 1974 (Halfpenny et al. pers. comm.). The boreal habitat in Colorado is isolated from similar habitat in Montana (Findley and Anderson 1956), making a natural recolonization from source populations unlikely. Therefore, Colorado Division of Wildlife (CDOW; now Colorado Parks and Wildlife) initiated a reintroduction program for Canada lynx in 1997 (Seidel et al. 1998). Between 1999 and 2006, 218 wild-caught lynx from Alaska and Canada were fitted with radio-telemetry/Argos collars and released in the San Juan Mountains (Devineau et al. 2010).

The southern Rocky Mountains consist of 'boreal islands' separated by large areas of non-boreal vegetation, in contrast to the relatively homogeneous boreal zone in Canada (Agee 2000). Snowshoe hares Lepus americanus, the primary prey source for lynx, have been observed in Colorado at densities equivalent to those during the low phase of population cycles in the northern boreal forests of Canada (Hodges 2000, Ivan et al. 2014), potentially due to the patchy and heterogeneous nature of spruce-fir habitat in the mountainous regions of
Colorado (Wolff 1980). The natural patchiness of optimal habitat may cause lynx in southern boreal forests to travel farther and more frequently to access an adequate amount of habitat (Aubry et al. 2000). Evidence also exists for large exploratory movements of lynx in southern boreal forests, a behavior that has not been observed in northern populations (Aubry et al. 2000).

Much of the published literature on Canada lynx focuses on northern populations, and Buskirk et al. (2000) caution against extrapolating this information to southern boreal populations, as climate, topography, and vegetation differ significantly over the broad geographic range. The available information on lynx dispersal and long distance movement in southern boreal forests is typically unpublished, consists of small sample sizes, or has incomplete spatial coverage. The reintroduction effort in Colorado has produced an extensive data set of spatial and demographic information for Canada lynx in southern boreal forests, a data set that is nearly impossible to replicate today.

Given that Canada lynx are endangered in the state of Colorado and Federally threatened (United States Fish and Wildlife Service 2014), information on their movement behavior can be of critical importance for management decisions. For example, the U.S. Forest Service and U.S. Fish and Wildlife Service have a Conservation Agreement that necessitated the identification of linkage areas for lynx that facilitate movement between and among parcels of lynx habitat (Claar et al. 2003). However, the linkage areas in Colorado have not been modified since 2002, shortly after the reintroduction program was initiated. Information from the reintroduced population, over the course of ten years, can be used to modify linkage area delineation. In addition to identifying temporal, spatial, and demographic patterns in movement behavior, we also explored the effect of the reintroduction on individual behavior.

\section{Material and methods}

Reintroduced individuals were released in the spring and fitted with either radio-telemetry radio collars (hereafter referred to as VHF collars; Telonics ${ }^{\mathrm{TM}}$, Mesa, AZ, USA) or VHF/Argos collars (Sirtrack ${ }^{\mathrm{TM}}$, Havelock North, New Zealand). Satellite transmitters were active for 12 consecutive hours per week, during which time several locations over those $12 \mathrm{~h}$ could be obtained using the Argos System (Devineau et al. 2010). Weekly airplane flights were conducted over a $20684 \mathrm{~km}^{2}$ area, which included the reintroduction area and surrounding high-elevation sites $(>2591 \mathrm{~m}$; Devineau et al. 2010); attempts were made to obtain a VHF location from each radio-collared individual in the study area once every 2 weeks. Additional flights outside of the study area were conducted when feasible and during the denning season (May-June; Devineau et al. 2010). Irregular location data were obtained from 1999-2011 due to one or both of the transmitter components failing, logistical constraints, or movement out of the study area that precluded consistent VHF data collection. Each winter, efforts were made to recapture reintroduced individuals and capture Coloradoborn individuals to maintain an adequate sample of working telemetry devices throughout the study period. 
There were sufficient data for modeling the movements of 153 of the 218 reintroduced Canada lynx, in addition to 12 Colorado-born lynx that were collared as adults $(\mathrm{n}=165$, Supplementary material Appendix 1). For certain individuals, time periods with missing data were large enough to cause computational stability issues; thus, based on preliminary analyses, we identified those cases and split the data into separate time series. The 216 resulting time series spanned 59-3947 d $($ mean $=756)$ and contained 26-1257 data points (mean $=202$; Supplementary material Appendix 1). Argos class $Z$ locations, which are conventionally deemed invalid, were removed from the data prior to analysis. Reproductive status of females was determined during denning season (May-June) through intense telemetry and den searches to locate females with dependent kittens each year; the breeding season was defined as February-April, summer as May-September, and winter as October-January.

\section{Movement model}

Our lynx data contains multiple data sources, large measurement error, temporal irregularities, and a coarse temporal resolution. These characteristics result in a data set that may not be amenable to analysis with contemporary mechanistic movement models (Jonsen et al. 2005, Johnson et al. 2008, McClintock et al. 2012). To overcome these challenges, we extended a Bayesian model developed by Buderman et al. (2016) for telemetry data that were collected at coarse spatial and temporal resolutions.

As an alternative to a mechanistic movement model, the process model developed by Buderman et al. (2016) approximates the underlying non-linear and complex movement behavior with linear combinations of basis functions. A basis function is a continuous function that can either transform an existing covariate in space or time, or act as a covariate itself; in ecology, basis functions are often used in generalized additive models (Wood and Augustin 2002), but are also used to model autocorrelated data (Hefley et al. 2017). In a movement context, multiple sets of basis functions operate as covariates that push or pull the movement process away from the geographic mean to create a representation of the underlying true path. The multiple sets of basis functions allow the movement behavior to change according to different temporal scales and allows for timevarying heterogeneity in movement without specifying or estimating the number of behavioral change-points or states (Jonsen et al. 2005, 2007, Gurarie et al. 2009, Hanks et al. 2011). The data component of the model presented by Buderman et al. (2016) uses multiple data sources to contribute to learning about the same underlying process, allowing us to use both VHF and Argos data, in contrast to other movement models that have been developed for use with a single error structure (Johnson et al. 2008, Breed et al. 2012, McClintock et al. 2014). Additionally, the model allows for data at irregular time intervals, alleviating the conventional need to impute missing data (Hooten et al. 2010, Hanks et al. 2011, 2015, Johnson et al. 2011). These characteristics result in a flexible, phenomenological model for animal movement that correctly accounts for multiple data sources and allows for temporally irregular and sparse data.

We generalized the model developed by Buderman et al. (2016) to allow for statistically rigorous populationlevel inference by simultaneously modeling the independent movement processes for multiple individuals (153 reintroduced and 12 Colorado-born lynx) using a shared data model component; this is in contrast to Buderman et al. (2016), where the two individuals were modeled completely independently from one another. The process model variance components were tuned at an individual level using predictive scoring over a two-step grid search of the parameter space. We fit the population-level model using a Markov Chain Monte Carlo (MCMC) algorithm written in $\mathrm{R}$ ( $\mathrm{R}$ Core Team), and posterior inference was based on 9000 MCMC iterations. Supplementary material Appendix 2 contains additional details for the model specification, estimated measurement error, and posterior mean trajectories of individuals.

\section{Characterizing movement}

In what follows, we use the word 'locations' to refer to modeled locations (the daily locations derived from the functional modeling framework). As the foundation for characterizing lynx movement behavior, we used the three quantities proposed by Buderman et al. (2016): residence time, speed, and tortuosity. Residence time was defined as the amount of time spent in a grid cell (the number of daily locations observed), and relative speed was calculated as the distance between sequential locations (because the modeled locations are regular in time, the distance is proportional to daily speed). We defined tortuosity as the degree to which individual's orientation at time $t$ deviates from time $t-\Delta t$, where large values indicate larger directional changes from one time to the next (we modeled locations daily, such that $\mathrm{t}-\Delta \mathrm{t}$ is equal to one day). Spatial and temporal derivations of each quantity are presented in Supplementary material Appendix 3 , as well as a guide to which analyses correspond to each quantity. The Bayesian framework allowed us to obtain posterior inference for derived quantities using Monte Carlo integration (Hobbs and Hooten 2015). Because the underlying movement process is modeled in continuous space and time, the derived quantities can be summarized spatially or temporally at any desired resolution. We calculated the temporal versions of speed and tortuosity at a daily resolution and used the posterior means as response variables in subsequent analyses.

An additional quantity was calculated by scaling speed and residence time by their maximum values and then dividing each by the sum of the two scaled quantities, such that the quantities can be viewed as the contribution to total behavior at that time. We describe three discretized behavioral modes based on the posterior means of these relative quantities: movement bouts, settlement locations, and exploratory movements. A movement bout was any time an individual's relative speed exceeded $50 \%$ of the contribution to total behavior (residence behavior is the complement). Settlement areas were identified as those locations where an individual's relative speed was equal to or less than $50 \%$ of 
the contribution to total behavior for more than 30 consecutive days, with initial settlement being the first location that resulted in a settlement (i.e. an initial home range). Exploratory movements were those locations that occurred between settlement locations following initial settlement.

We used linear mixed models with an individual random intercept for any analysis with multiple measurements per individual (R package 'lme4'; Bates et al. 2014). Individuals that were split into separate time series for fitting the movement model were considered as the same individual in subsequent analysis. In all cases, the response variable was log-transformed and the mean and 95\% Wald confidence interval for the fixed effects were presented on the real scale (due to the transformation, this results in geometric, not arithmetic, means). For analyses with a single response variable per individual we present the sample arithmetic mean and range across individuals. Likelihood ratio tests were used for model comparison.

\section{Movement summary statistics}

Daily speed, daily tortuosity, and duration of completed movement bouts were modeled as a function of sex, season, and reproductive status (for females). Patterns in movement initiation dates were determined by calculating the proportion of individuals that performed movement bouts compared to the number that could have performed a movement bout at that time. Finally, total distance moved from first to last location for each individual was calculated as the sum of the daily posterior mean speeds.

\section{Reintroduction and exploratory movement}

Of the 153 reintroduced individuals with sufficient data, 18 had large gaps between the reintroduction date and first modeled location, three had subsequent missing data before initial settlement, and four settled within a day of their release. These individuals were removed from the analysis of movement from reintroduction to initial settlement, resulting in 128 individuals. To determine the immediate post-reintroduction behavior of lynx, given that they did not settle immediately after release, we calculated time from reintroduction to initial settlement, total distance moved from reintroduction to initial settlement, and straight-line distance from reintroduction to initial settlement as response variables in linear mixed models.

Temporal duration and distance of exploratory movements for reintroduced individuals following initial settlement were modeled as functions of sex. An additional 36 of the 128 individuals only completed an initial settlement and three had missing values during their only exploratory movement, leaving 89 individuals who performed a total of 196 exploratory movements (excluding those with missing data).

To investigate the effect of reintroduction on movement behavior, we compared annual 6-month periods that corresponded to the same date range as the first 6-months after an individual's release (e.g. 1 January, 1999 to 1 June, 1999 vs 1 January, 2000 to 1 June, 2000, etc.). We analyzed a subset of individuals with multiple years of data and compared speed and tortuosity across years. We modeled data up to $7 \mathrm{yr}$ following release because few individuals remained telemetered longer than that. To account for the increasing population size as the reintroduction progressed, we modeled daily speed and tortuosity during the first 6-month period following an individual's release as a function of the year since the reintroduction was initiated (1999).

To quantify the return rate to a previous settlement location, we modified the clusGap function (R package 'cluster'; Maechler et al. 2013) to use the Haversine formula for great-circle distance (R package 'cluster'; Hijmans 2015) and calculated the optimal number of geographic clusters among settlement locations. Of 165 individuals (153 reintroduced individuals plus 12 Colorado-born individuals), nine individuals were never observed settling in a location for more than $30 \mathrm{~d}$ and 40 only settled once (including two Colorado-born lynx). A remaining 40 individuals had inconclusive clustering results, which were indicated by the algorithm separating a single residence period into multiple geographic clusters (likely caused by slow unidirectional movement). Inference for return rates was obtained for the remaining 77 individuals that were observed settling more than once.

\section{Correlations between vegetation and movement}

We used LANDFIRE (2008) data to assess correlations between habitat characteristics and movement bouts (indicating connectivity) and non-movement locations. Because of the large extent of the study area, we reclassified the 120 relevant LANDFIRE classes into 16 categories: agriculture, urban/developed, riparian willow, riparian non-willow (e.g. cottonwood, poplar, sedge, exotic), grassland/rangeland, water, barren (rock/snow/ice/talus), alpine/subalpine tundra/meadow, montane shrubland (e.g. Gambel oak, mesic mountain shrub, serviceberry, snowberry), xeric shrubland (e.g. sagebrush, saltbrush, greasewood), spruce-fir, mixed spruce-fir (e.g. spruce with Douglas fir, lodgepole, or aspen), pinyon-juniper, aspen, lodgepole pine, and montane mixed forest. We then extracted the raster values for times when individuals were and were not performing a movement bout.

\section{Connectivity and residence area identification}

To identify areas of connectivity, we divided the western United States into equally sized grid cells (0.15 degree $\left.{ }^{2}\right)$ with boundaries determined by the minimum and maximum location values. The grid cell representation of the spatial surface facilitates computation, with smaller grid cells more closely approximating a continuous surface. To obtain population-level spatial quantities, we calculated the sum across individuals of the per grid cell posterior mean, such that the quantity represents the total mean behavior for any of the 165 individuals that entered that grid cell from 1999-2011. For example, cells with large values for speed indicated areas where lynx moved quickly (i.e. what we assume represent long distance movement behavior and thus indicates connectivity), or areas where many slow moving lynx aggregated (see Supplementary material Appendix 4 for population averaged quantities). Assessing speed and residence time together can highlight those areas used for high-speed movements. Connectivity areas were indicated by areas of high speed and low residence time behavior, whereas residence areas were identified by large values for residence time. 

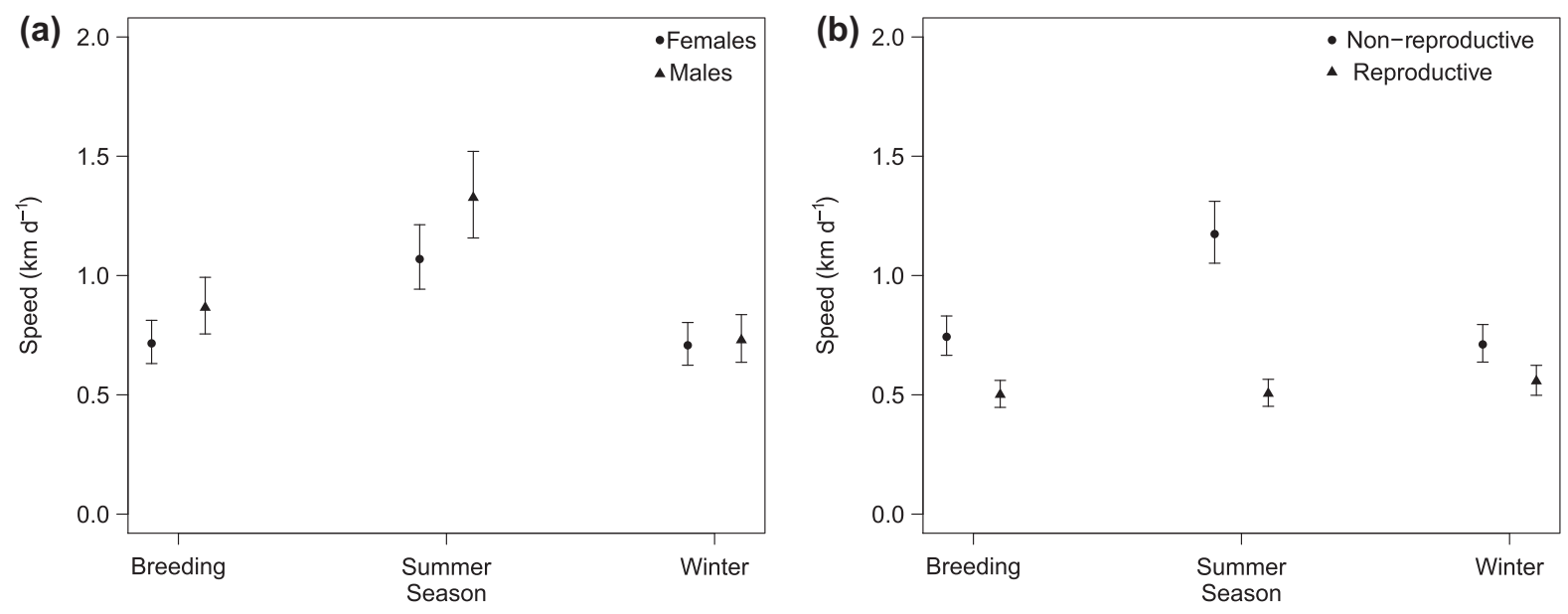

Figure 1. Mean daily speeds, and 95\% confidence intervals, for Canada lynx as a function of season and sex (a). Mean daily speeds, and $95 \%$ confidence intervals, for female lynx (b) as a function of season and reproductive status. The breeding season was defined as February-April, summer as May-September, and winter as October-January.

\section{Results}

\section{Movement summary statistics}

Using a random effect for individual, we did not observe a statistically significant effect of sex on daily speed $\left(\chi^{2}(1)=2.28, p=0.12\right)$ : average daily speed was $0.93 \mathrm{~km}$ $\mathrm{d}^{-1}(\mathrm{CI}=0.85-1.03)$. However, a season effect was statistically significantly $\left(\chi^{2}(2)=13778, p<0.0001\right)$, and a season by sex interaction improved the model over just a season effect $\left(\chi^{2}(3)=463, \mathrm{p}<0.0001\right.$; Fig. 1a). Using the season-by-sex interaction model, we found that both females and males exhibited greater daily speeds during the summer months (Fig. 1a). On average, males moved slightly faster than females, but this difference was greatest during the summer months (Fig. 1a). An interaction between season and female reproductive status was significant $\left(\chi^{2}(3)=6476, p<0.0001\right.$; Fig. 1b), with non-reproductive lynx consistently moving faster than reproductive lynx.
Speeds during the winter months were similar, regardless of reproductive status, but non-reproductive individuals moved significantly faster during the breeding and summer months (when the difference between groups was greatest; Fig. 1b).

Using a random effect for individual, we found that sex did not have a statistically significant effect on daily tortuosity $\left(\chi^{2}(1)=1.15, p=0.28\right)$ : average daily tortuosity was

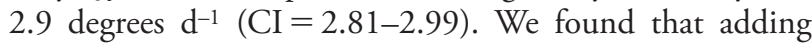
season as a fixed effect significantly improved the model $\left(\chi^{2}(2)=1739, \mathrm{p}<0.0001\right)$, while an additional interaction between season and sex did not $\left(\chi^{2}(3)=4.21, \mathrm{p}=0.24\right)$. Average daily tortuosity, using the model with a seasonby-sex interaction, showed that values for tortuosity were lowest in the summer for both sexes (Fig. 2a). Female movement paths varied in tortuosity by reproductive status and season, with reproductive individuals having more tortuous movements, particularly in the summer $\left(\chi^{2}(3)=477\right.$, $\mathrm{p}<0.0001$; Fig. 2b).
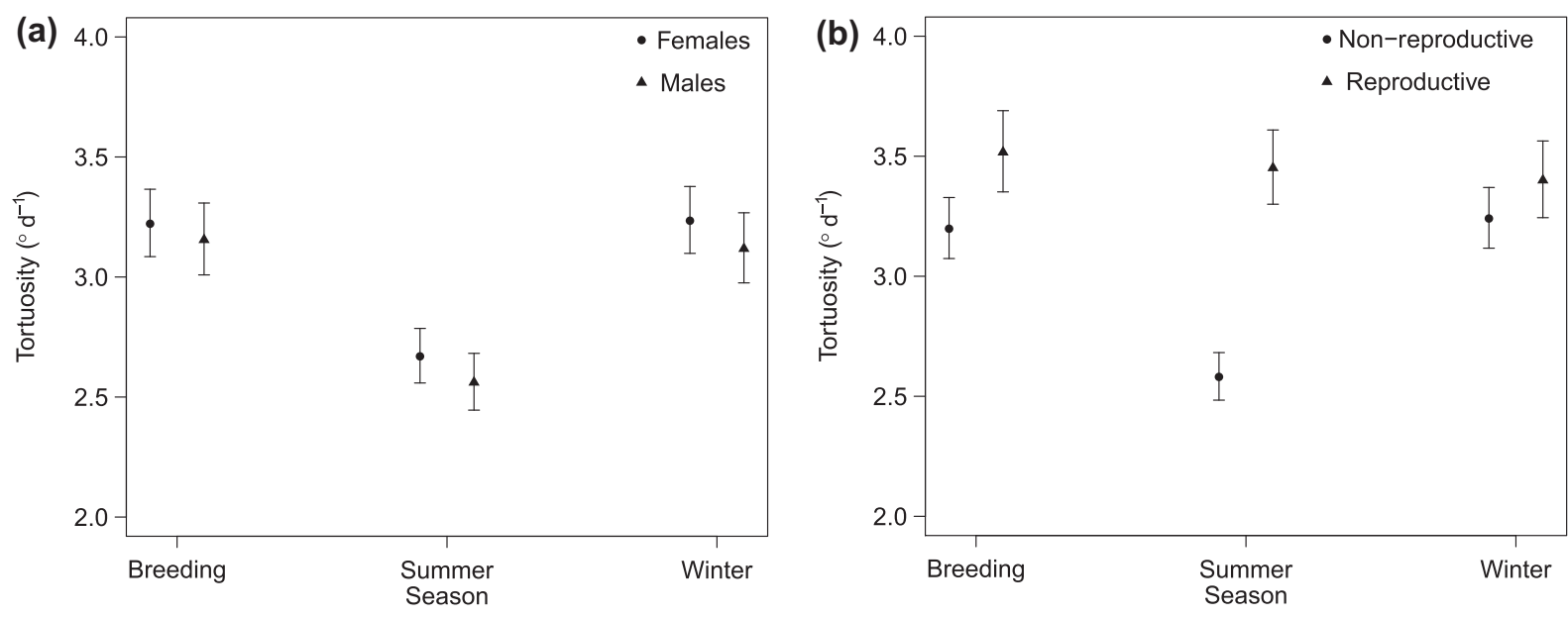

Figure 2. Mean daily tortuosity, and $95 \%$ confidence intervals, for Canada lynx as a function of sex and season (a). For consistency, we present the results from the model with a sex-by-season interaction, although the addition of season did not significantly improve the model. Tortuosity of females (b) was a function of both season and reproductive status. The breeding season was defined as February-April, summer as May-September, and winter as October-January. 

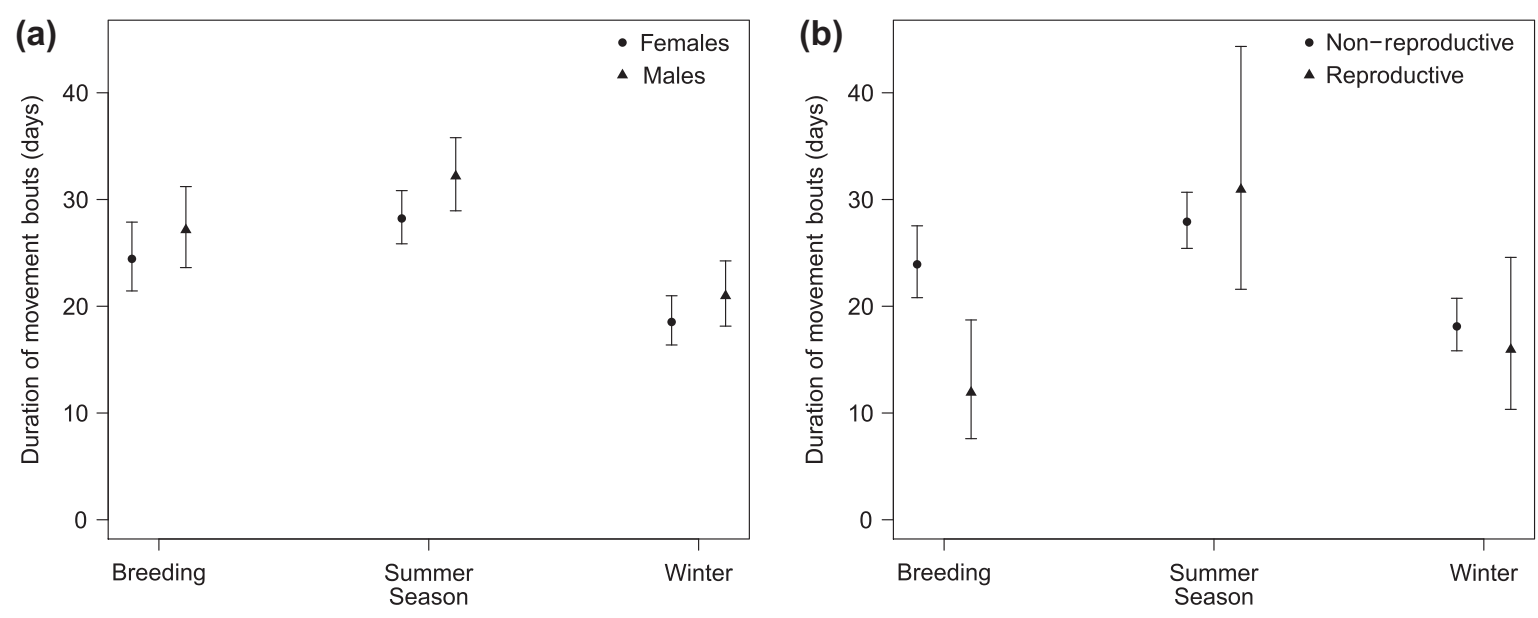

Figure 3. Mean duration, and 95\% confidence intervals, of movement bouts made by Canada lynx as a function of sex and season (a). For consistency, we present the results from the model with a sex-by-season interaction, although the addition of season did not significantly improve the model. We detected an interaction between season and reproductive status on the duration of movement bouts by female lynx (b). The breeding season was defined as February-April, summer as May-September, and winter as October-January.

Accounting for sex marginally improved the model for duration of movement bouts $\left(\chi^{2}(1)=3.73, \mathrm{p}=0.05\right)$. On average, the duration of movement bouts was $25 \mathrm{~d}$ for females $(\mathrm{CI}=23-27)$ and $28 \mathrm{~d}$ for males $(\mathrm{CI}=26-30)$. One female and one male spent over $200 \mathrm{~d}$ in a continuous movement bout. We did find a seasonal effect on the duration of movement $\left(\chi^{2}(3)=736, \mathrm{p}<0.0001\right)$, but a model with a season by sex interaction did not perform better than a model with just a season effect $\left(\chi^{2}(3)=4.46, p=0.22\right)$. The average duration of a male movement bout lasted slightly longer than a female's, but the difference was greatest during the breeding season and summer (Fig. 3a). We found evidence for an interaction between season and reproductive status on duration of movement bouts for females $\left(\chi^{2}(3)=8.73\right.$, $\mathrm{p}=0.03$; Fig. $3 \mathrm{~b}$ ). During breeding season, reproductive females made shorter movement bouts than non-reproductive females (Fig. 3b).

Aggregating across years for each sex, we found a slight difference in the proportion of males and females performing movement bouts, particularly in April, May, and June (Fig. 4). From reintroduction to last location (either mortality or collar failure, excluding the distance potentially moved between non-modeled time periods), females moved, on average, a total distance of $1322 \mathrm{~km}$ (range $=139-4116)$ and males moved $1367 \mathrm{~km}$ $($ range $=136-5841)$.

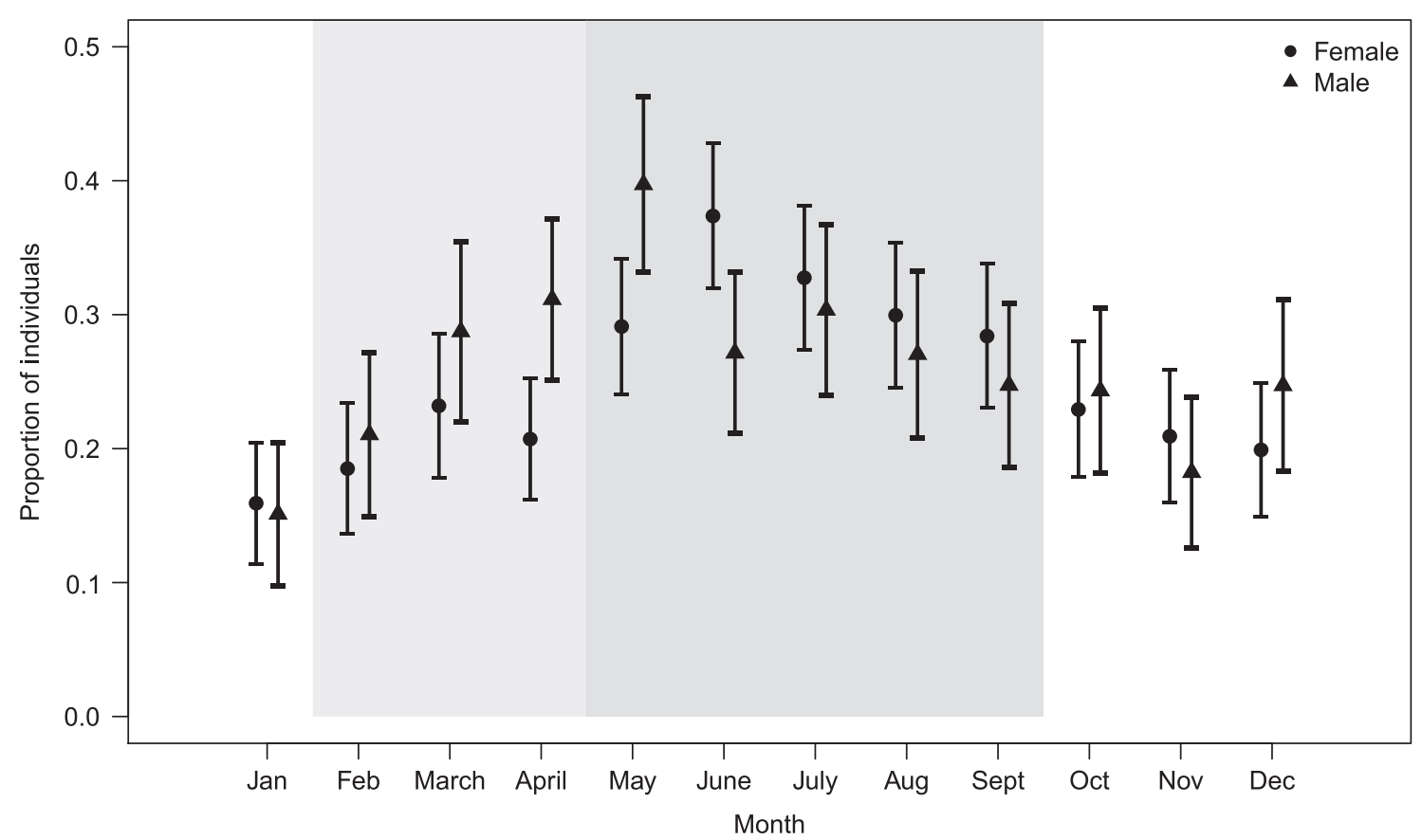

Figure 4. Proportion of the Canada lynx that made a movement bout in a given month across all years of the study (1999-2011). Light gray shading indicates breeding season, and dark gray indicates summer. 

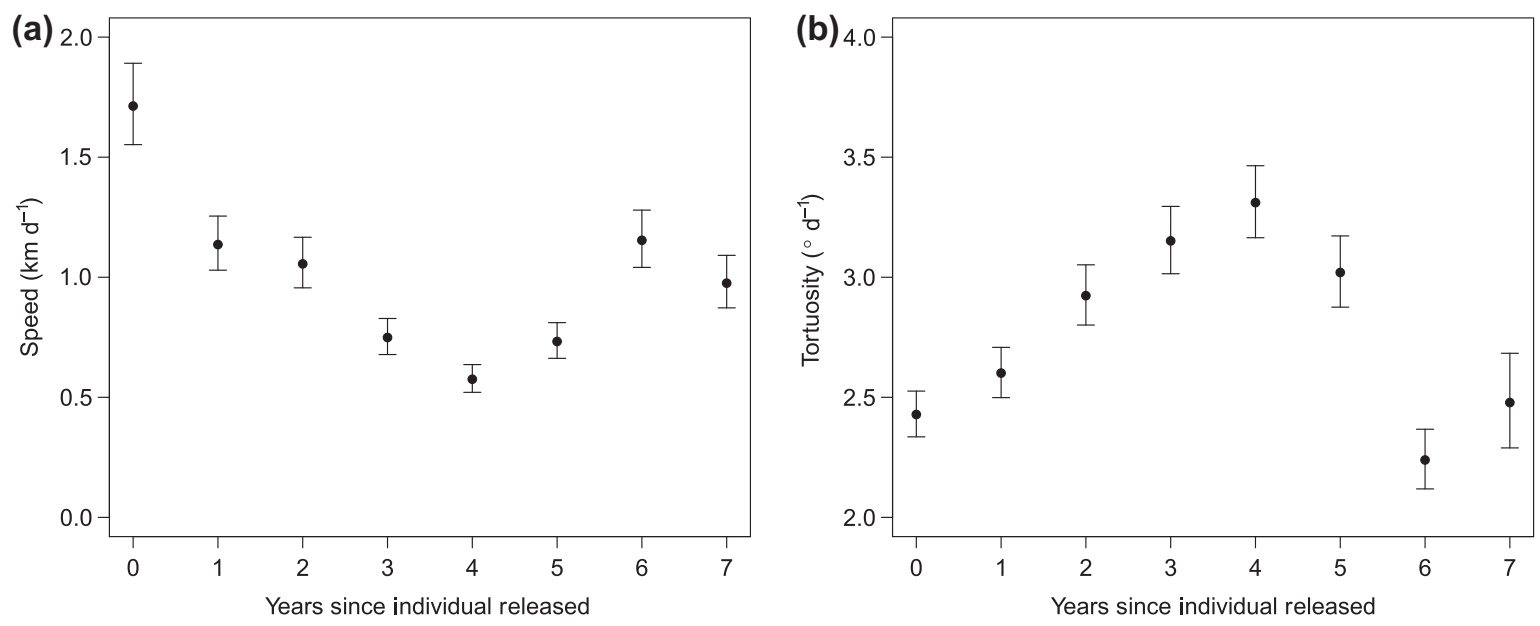

Figure 5. Mean daily speed (a) and tortuosity (b) of Canada lynx as a function of years since their release. The decrease/increase in speed/ tortuosity up to year is likely a result of individual's increasing familiarity with the landscape, while anecdotally older lynx (those that have survived 5 + years) tend to become nomadic.

\section{Reintroduction and exploratory behavior}

On average, given that they did not settle within one day of release, females and males spent over 5 months moving before establishing an initial settlement area (females: mean $=157 \mathrm{~d}$, range $=4-571$; males: mean $=179 \mathrm{~d}$, range $=3-624)$. Mean total distance traveled from the reintroduction site to first settlement was $449 \mathrm{~km}$ for females (range $=4-2805)$ and $519 \mathrm{~km}$ for males (range $=4-1414)$. Standardizing by the number of days available to move, females and males moved, on average, $2.8 \mathrm{~km} \mathrm{~d}^{-1}$ (females: range $=0.4-6.4$; males: range $=0.5-6.6$ ). The reintroduction site and the initial settlement site were $96 \mathrm{~km}$ apart for females (range $=2-766$ ) and $126 \mathrm{~km}$ apart for males (range $=6-643$ ).

On average, given that an individual settled more than once, each individual performed 2.2 exploratory movements. Sex was not a significant predictor for the duration of exploratory movements $\left(\chi^{2}(1)=1.96, p=0.16\right)$, which was, on average, $72 \mathrm{~d}(\mathrm{CI}=62-85)$. Sex was also not a significant predictor for the total distance moved during exploratory

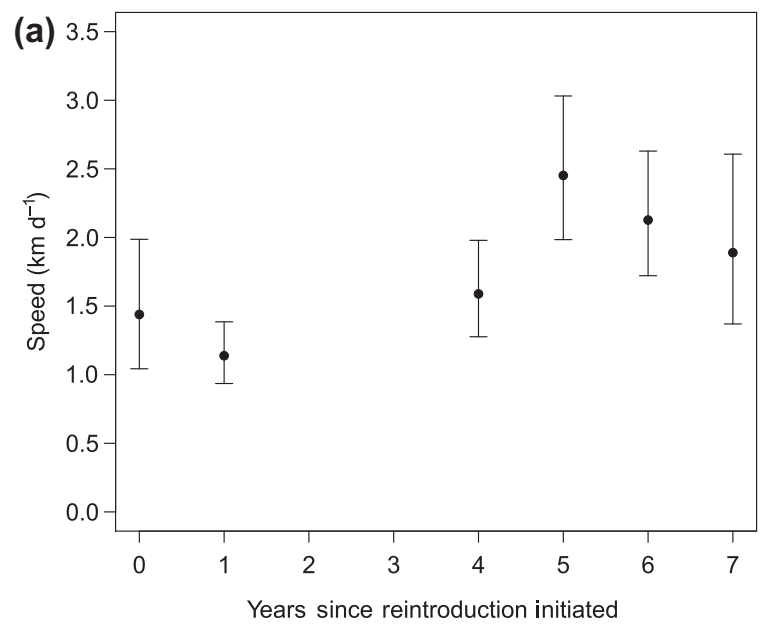

movements $\left(\chi^{2}(1)=1.63, \mathrm{p}=0.2\right)$, which was, on average, $107 \mathrm{~km}(\mathrm{CI}=82-139)$. Of the 196 exploratory movements, $44 \%$ were in the summer, $35 \%$ were in the breeding season, and $21 \%$ were in winter.

Daily speed decreased steadily over the first four years following an individual's release but then increased (Fig. 5a). We also saw increasing values for daily tortuosity, which indicates that an individual is covering less ground from one day to the next (constrained movement within an area; Fig. 5b). Accounting for the year since the reintroduction was initiated significantly improved the model for daily speed and tortuosity during the first 6 months following an individual's release $\left(\chi^{2}(6)=107, \mathrm{p}<0.0001\right.$ and $\chi^{2}(6)=354, p<0.0001$, respectively). Although the $95 \%$ confidence intervals overlap, there is a suggestion that speed was higher (Fig. 6a) and tortuosity lower (Fig. 6b) as time since the reintroduction increased.

Of the 77 individuals that settled more than once, 26 never settled in the same location more than once. The remaining individuals used the same location for a settlement area 2-10 times, and those reused settlement areas

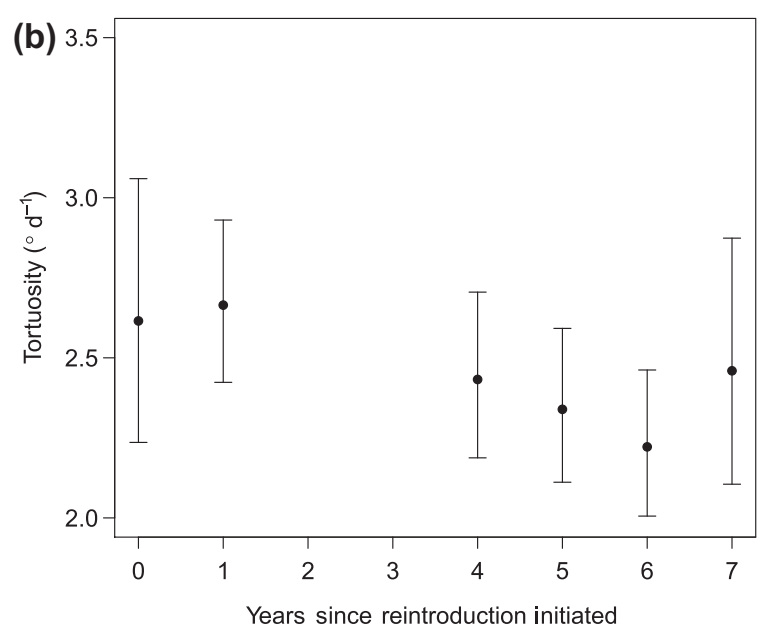

Figure 6. Mean daily speed (a) and tortuosity (b) of Canada lynx during their first year in Colorado as a function of years since the reintroduction program was initiated. 
often constituted a large percentage of their total settlements (Table 1). In addition, one individual used two separate settlement areas more than once.

\section{Correlations between vegetation and movement}

Approximately $56 \%$ of non-movement bout locations occurred in spruce/fir habitat, with an additional $12 \%$ and $10 \%$ occurring in aspen and alpine/subalpine habitat, respectively. Habitat designated as barren contained $10 \%$ of non-movement bout locations. All other habitat was associated with less than $3 \%$ of the residence locations. Movement bout locations also occurred predominately in spruce/fir habitat (40\%), aspen (15\%), and alpine/subalpine habitat (9\%). Barren habitat contained $8 \%$ of movement bout locations. However, a greater proportion of movement locations occurred in alternative habitat compared to non-movement locations. For example, $7 \%$ of movement locations occurred in xeric shrublands, and $4 \%$ occurred in each of lodgepole pine habitat and montane mixed forest.

\section{Connectivity and residence area identification}

Values for residence time were largest in the San Juan Mountains of southwest Colorado, between the towns of Silverton and Creede (this area encompasses the reintroduction area; Fig. 7a). Large values for residence time, compared to the surrounding area, can also be seen in the Sawatch Range in the central part of the State, approximately 40 $\mathrm{km}$ east of Aspen (Fig. 7a). At a population-level, individuals spent little time outside of the reintroduction area in Colorado (Fig. 7b).

Within Colorado, population-level speeds were highest in the San Juan Mountains in southwest Colorado (Fig. $7 \mathrm{c})$. The overlap with areas of high residence time was likely because the summation will result in similarly large speeds if a grid cell contained a small number of fast individuals or a large number of slow individuals. Therefore, areas of high residence time may also be areas of high speeds (see Supplementary material Appendix 4 for alternative quantities that account for the number of individuals using a cell and the posterior mean number of individuals that were observed in a cell). However, peak speeds in areas with low residence time (e.g. connectivity areas) occurred northeast of the town of Creede (i.e. east of the area where residence time peaked) at the base of a population-level path that extended along the Continental Divide through the Sawatch, Mosquito, and Front Ranges of Colorado before entering Wyoming (Fig. 7c). From southern Wyoming, trajectories fork and dissipate as they move westward toward the Wind River, Wyoming, and Uinta Ranges and northward toward the Bighorn Mountains (Fig. 7d). Multiple individuals that left Colorado used an area in the southern portion of Wyoming with individual paths intersecting at multiple points along the western border of Wyoming, but, proportionally, only a few individuals utilized these areas (Fig. 7d).

The largest values for tortuosity correspond to the same areas as for residence time (Fig. 7e). However, large values for population-level tortuosity also extended beyond the high residence time area (to the northwest and to the northeast along portions of the path to Wyoming), suggesting a boundary area where individuals spent time exploring but not settling (Fig. 7e).

\section{Discussion}

\section{Overview of findings}

Generally, lynx moved at greater speeds and with lower tortuosity during summer compared to winter. Males moved slightly faster than females in summer, and non-reproductive females moved faster and in less tortuous paths than reproductive females during the breeding and summer seasons. Proportionally more individuals engaged in movement bouts during summer compared to other seasons. We found that reintroduced lynx spent an average of 5 months in a movement bout, given that they did not settle within one day of release, before establishing an initial settlement area (i.e. an initial home range). Locations of initial settlement areas averaged approximately $100 \mathrm{~km}$ from the release site. After initial settlement, more than half of the individuals engaged in at least one exploratory movement that lasted an average of $72 \mathrm{~d}$, covered an average of $107 \mathrm{~km}$, and occurred mostly during the breeding and summer seasons. Many individuals returned to the same settlement area after making an exploratory movement. Areas traversed during movement bouts generally encompassed larger proportions of alternative habitat (e.g. xeric shrublands, lodgepole pine forest, montane mixed conifer forest) than those used during non-movement bouts (e.g. spruce/fir forest, aspen, alpine or subalpine meadows). Residence behavior occurred mostly in southwest and central Colorado; however, we observed a population-level corridor of high-speed movement that extended from the southwest part of Colorado, through the central mountain ranges, and dissipated in southern Wyoming. While we can compare these findings to what has been seen in other southern lynx populations (Poole 1997, Burdett et al. 2007, Squires et al. 2013), our study is unique in that the inference directly relates to conditions following a reintroduction.

Table 1. Number of Canada lynx that used the same settlement area a given number of times, along with the range in the percentage of settlements occurring in the same area. Settlement areas were defined as those locations where an individual's relative speed was equal to or less than $50 \%$ of the contribution to total behavior for more than 30 consecutive days. A total of 29 individuals never settled more than once in the same location and one individual used more than one settlement area more than once (resulting in an additional 'individual' in the table).

\begin{tabular}{llcccrrrrr}
\hline & \multicolumn{1}{c}{ Number of times a settlement area was reused } \\
\cline { 2 - 10 } & \multicolumn{1}{c}{2} & 3 & 4 & 5 & 6 & 7 & 8 & 9 & 10 \\
\hline Returning individuals & 22 & 9 & 7 & 6 & 5 & 1 & 0 & 0 & 1 \\
Percentage of settlements & $40-100$ & $60-100$ & 100 & $83-100$ & 100 & 100 & NA & NA & 100 \\
\hline
\end{tabular}


(a)

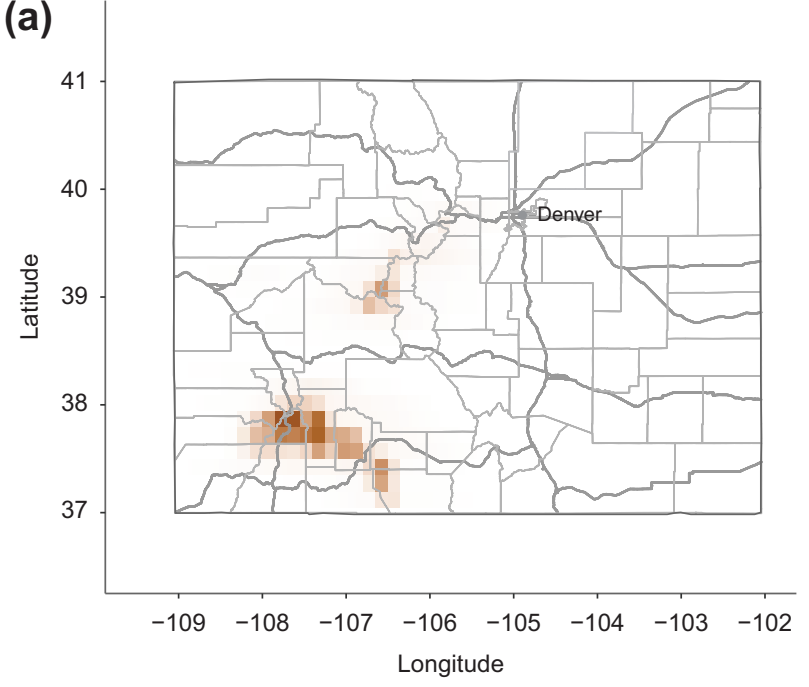

(c)

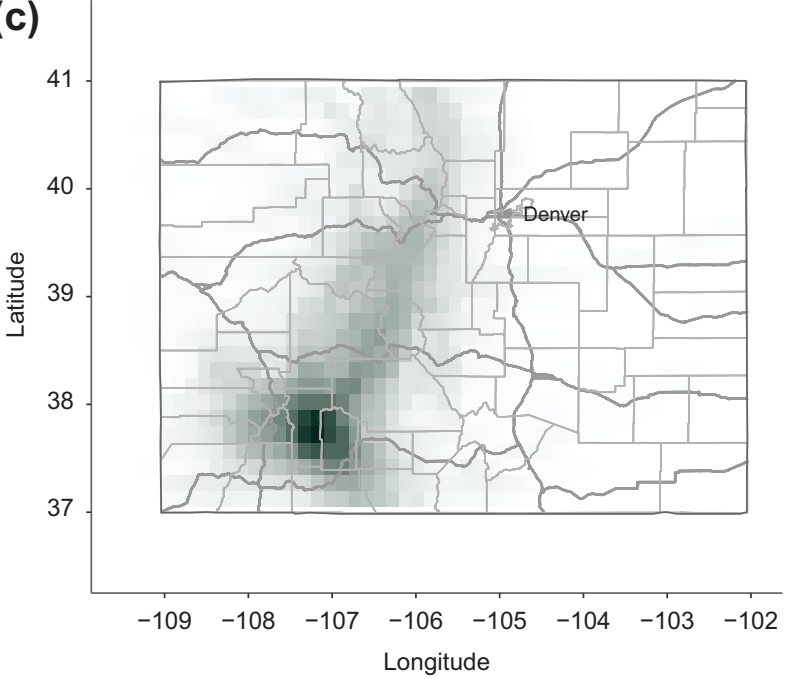

(e)

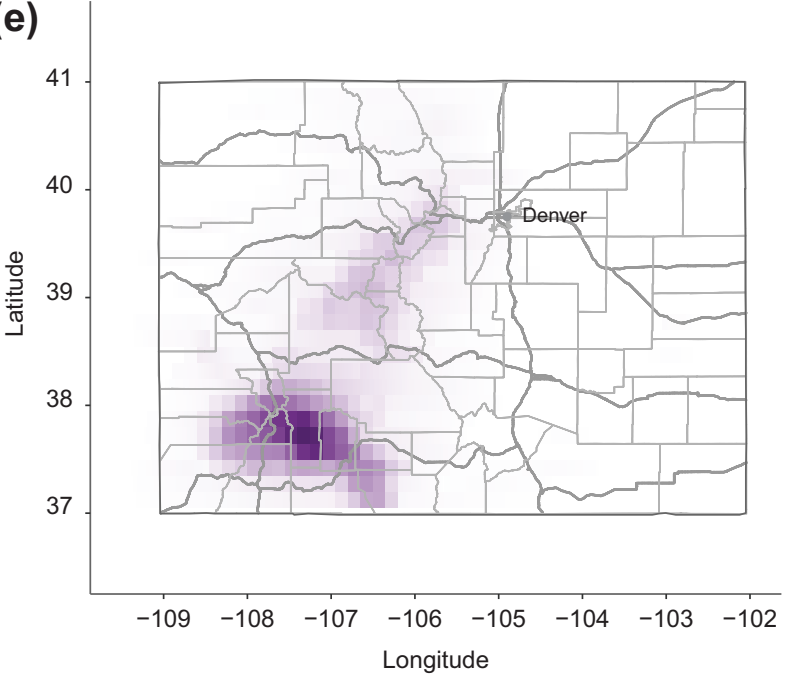

(b)

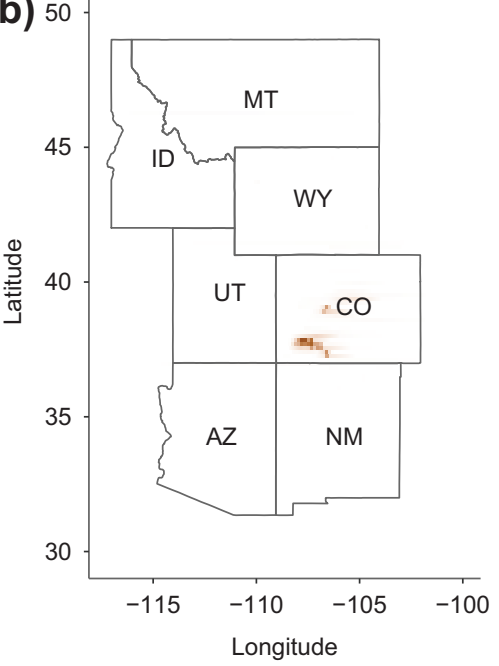

(d) 50

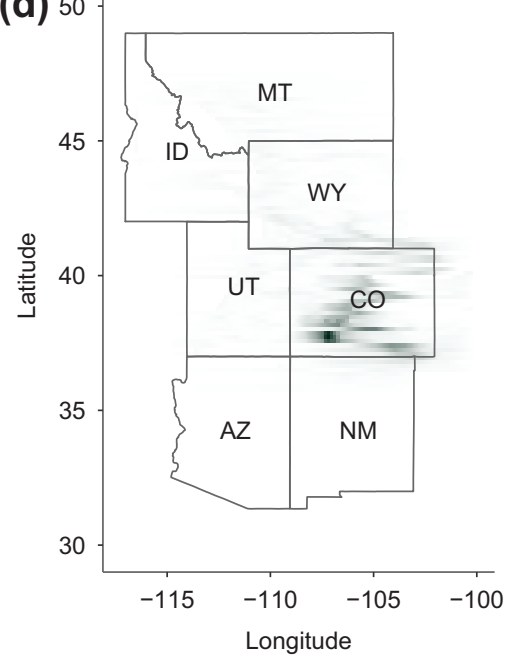

(f)

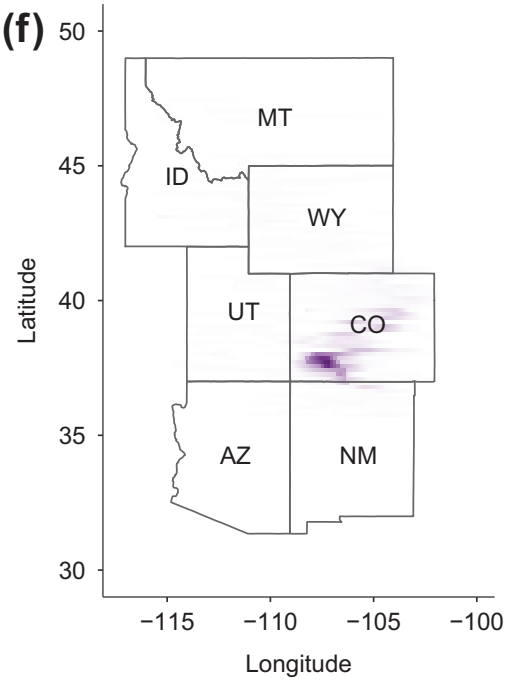

Figure 7. Population-level spatial quantities of residence time (a, b), speed (c, d), and tortuosity (e, f). For reference, county boundaries and major roads are shown for Colorado (a, c, e). Not included are rare movements to eastern states (Nebraska, Kansas, and Iowa). 


\section{Inference for movement of reintroduced Canada lynx in Colorado}

Squires et al. (2013) found that lynx movement rates in the Northern Rocky Mountains averaged $6.9 \mathrm{~km} \mathrm{~d}^{-1}$, which is considerably higher than those reported in northern populations during periods of high hare density but similar to those during cyclic lows. We found lower daily speeds, however the fine-scale movement information obtained by Squires et al. (2013) may account for this difference. There are many small-scale movements made by lynx that our model would fail to detect, because speed was calculated as the difference between daily locations. Our estimates of tortuosity represent the difference in direction of movement from one day to the next, therefore, as with speed, these estimates do not include the many fine-scale directional changes that lynx perform within a $24-\mathrm{h}$ period. Due to the resolution of the data, the splines used in this analysis were not intended to detect movement at a fine scale. However, the relative values of these estimates are still informative for distinguishing between behaviors that occur at relevant time-scales (e.g. days as opposed to hours). Directed movement paths (low tortuosity), such as those observed in Colorado, are typical for populations in marginal or patchy habitat, and may indicate that these lower elevation montane zones are facilitating movements between primary habitat blocks (Ruediger et al. 2000). Fuller and Harrison (2010) found similar results for Canada lynx in northwestern Maine, where paths were more tortuous in habitat with greater densities of snowshoe hares. Comparable patterns have also been observed in other species; for example, Davies et al. (2013) found that koalas demonstrated highly torturous paths within habitat patches, and more linear paths when moving between patches.

While Poole (1997) considered dispersal in the Northwest Territories to occur when an individual Canada lynx moved $\geq 5 \mathrm{~km}$ from the boundary of a home range, and anything less to be an exploratory movement, we found that individuals often returned to a settlement location after traveling distances larger than $5 \mathrm{~km}$. However, similar to Poole (1997), we did not find that sex was an important factor in the total distance moved by lynx. We did find a difference in the duration of movement bouts by season, with both males and females spending more time in a continuous movement bout in the breeding season and summer compared to winter. Burdett et al. (2007) also found that some male lynx in Minnesota exhibited increased movements during the month of March, which was encompassed by our designated breeding season, while female lynx had the smallest home ranges during the summer months, when they were more closely associated with the den site. Therefore, we expected non-reproductive females to exhibit more movement behavior, because they are not spatially constrained. While the uncertainty in mean duration of a summer movement bout was large for reproductive females, we did find that nonreproductive females engaged in longer movement bouts during the breeding season.

In addition, some individuals traveled extremely large distances (e.g. $>1000 \mathrm{~km}$ ). The majority of these individuals, particularly those moving east, were unlikely to be reproductively successful because there are no lynx populations in the central United States. Some individuals did move through potential lynx habitat in Montana where individuals could have encountered other lynx. Individuals that moved large distances traveled across significant stretches of marginal habitat, however their mortality risk may have been higher than individuals that did not leave the reintroduction area. For example, $20 \%$ of reintroduced Colorado lynx mortalities were due to vehicle collisions (Devineau et al. 2010), similar to the $19 \%$ seen following their reintroduction to the Adirondack Mountains (Aubry et al. 2000).

Our analysis suggests that individuals make longer movements at faster speeds during the first few years following release; this is is not an uncommon finding for reintroduction programs. For example, Rosatte and MacInnes (1989) found that exploratory movements and home ranges were many times greater for relocated urban raccoons Procyon lotor compared to non-relocated individuals. In addition, individuals that were relocated to a rural area, as opposed to a town, had a stronger response to the relocation, possibly due to a lack of familiarity with the surrounding area (Rosatte and MacInnes 1989). The boreal habitat in Colorado is known to be more patchy and heterogeneous than boreal habitat in Canada and Alaska (Agee 2000). These habitat differences may be sufficient to result in exploratory movements. In a reintroduced population of Eurasian lynx Lynx lynx, Vandel et al. (2006) found that some individuals made exploratory movements during the first three months of being released, a behavior that gradually declined and ended with the individuals establishing a home range near or centered on the release site. In contrast, very few lynx in our study settled at the release site, and many individuals moved a large distance before initial settlement, often geographically far from the release site. This could be due to the large number of individuals released at a limited number of release sites.

Time since release has been shown to be an important factor in determining movement behaviors (e.g. distance between release and settlement sites, tortuosity) across species (Wear et al. 2005). For example, while $13 \%$ of a reintroduced black bear Ursus americanus population returned to their capture site (approximately $160 \mathrm{~km}$ away) the nonhoming individuals reduced their mean daily movements during the first month post-reintroduction (Wear et al. 2005). del Mar Delgado et al. (2009) found that eagle owls Bubo bubo in the wandering phase of dispersal had less tortuous paths than individuals in the stop phase of dispersal (initiated after an individual finds a temporary settlement area), which, in turn, had less tortuous paths than territorial individuals; they suspected that changes in tortuosity are a function of familiarity with the landscape. Lynx exhibited a similar pattern, exhibiting decreased daily speed and increased tortuosity as they had been present on the landscape for longer. The reintroduction effect in our study may also be confounded with individual age. Anecdotally, older age classes of lynx in Colorado are more likely to become nomadic, which is corroborated by the increase in daily lynx speeds at $5+$ years since being released (J. Ivan, CPW, pers. comm). In addition, this population was reproductively successful, therefore the effect of reintroduction on movement was not ubiquitous enough to hinder the success of the reintroduction. 
Squires et al. (2013) assumed that lynx respond similarly to the landscape during dispersal event as they would within their home-range. However, habitat selection depends on the resources available to the individual (Johnson 1980) and the costs associated with a particular habitat (Morris 1992), which may vary across behaviors. For example Killeen et al. (2014), found that dispersing elk Cervus canadensis did not respond to NDVI (a measure of landscape productivity), whereas resident elk showed a strong positive relationship to NDVI. Similarly, Morrison et al. (2015) found that selection for open water, roads, and elevation differed between cougars Puma concolor establishing temporary home ranges and those making exploratory movements. While we found some similarities in the habitat types used by lynx during movement and non-movement behavior, a greater proportion of movement bout locations occurred in xeric shrublands, lodgepole pine, and montane mixed forest compared to nonmovement bout locations.

Based on the modeled movement of individuals from 1999-2011, we identified an area of high connectivity at the population-level in the Front Range. Our results indicate that a substantial subset of individuals ventured beyond the reintroduction area, predominately to the north, both before and after initial settlement into a home range. However, the area of connectivity (indicated by high speed) we identified within Colorado is very wide, due to uncertainty in the individual movement paths and large amounts of individual variation. Therefore, it is unlikely that the concept of a linear corridor connecting habitat patches is applicable for Canada lynx in Colorado. Cushman et al. (2009) believed that the concept of a corridor is limiting to the idea of connectivity, and connectivity should be considered broadly as the ability of an individual to traverse a landscape with variable resistance. Lynx were also observed using diffuse corridors, similar to those we observed north of Colorado, through varying habitat quality near the southern limit of their range in Canada, indicating that this type of behavior may be a function of the patchy landscape (Walpole et al. 2012).

The area of high connectivity we identified along the Front Range from 1999-2011 may have changed as a function of intraspecific interactions (e.g. long-term settlement in areas previously used for movement between high quality habitats), although the population density is likely still low due to the population being at the southern periphery of their range where boreal forest is naturally patchy (Aubry et al. 2000). Although uncertainty was high, we found evidence for new individuals making movements of higher speeds and lower turning angles as the number of years since the reintroduction was initiated increased, which may be a function of increasing lynx density at the reintroduction sites. Additionally, we did not explicitly account for temporal changes to the landscape (e.g. weather patterns at the reintroduction sites, amount of understory vegetation), therefore we cannot assume that the changes in lynx behavior over time are solely a function of lynx density. However, evidence for reintroduced lynx and their offspring using specific areas of Colorado can still inform where conservation efforts should be focused, while acknowledging that no single corridor will provide connectivity across all individuals.

\section{Modeling framework}

We demonstrated that extensions to the modeling framework presented by Buderman et al. (2016) were able to provide insight into movement of Canada lynx following their reintroduction to the Colorado. Using a statistical model for telemetry locations properly accounts for measurement error, which is present in the raw locations, and allows for continuous-time inference on how the animal is moving, not just where it was observed. While our Canada lynx data set requires a generalized form of the data model presented in Buderman et al. (2016), other data models, such as those for GPS locations, can be used in place of the one presented here, which is specific to combinations of Argos and VHF data. A version of the functional movement modeling approach with a simplified data model has been implemented in standard statistical software (R package 'ctmcmove'; Hanks 2016). In addition, if locations are collected more frequently in time than the lynx data were, then fine-scale basis functions can be used to detect smaller changes in movement behavior. We also note that our definitions for movement bouts, settlement locations, and exploratory movements can be modified to either match the definitions used by other studies or to reflect a different quantity of interest.

Some movement analyses explicitly link movement to resource selection, typically using step-selection functions. However, most step-selection function models do not account for measurement error (Fortin et al. 2005, Forester et al. 2009, Avgar et al. 2016). While the spatio-temporal point process of Brost et al. (2015) is more general and incorporates measurement error into a resource selection framework, it is computationally intensive (Hooten et al. 2017). The continuous-time discrete-space model developed by Hanks et al. (2015) could be used for analyzing drivers of lynx movement over short temporal spans, but the memory requirements for fitting the model across multiple years would exceed the current storage capabilities of most statistical software. In addition, the large amount of path uncertainty introduced by both the Argos error and the large temporal gaps in the time-series would inflate the uncertainty associated with inference on movement drivers. However, linking contemporary lynx movements to spatial covariates would provide natural resource agencies with additional information that could be incorporated into predictive models for evaluating impacts of landscape-level management actions and should be the subject of future research.

Throughout the manuscript we refer to obtaining 'population-level' inference, by which we mean evidence of consistent behavioral responses across sampled individuals, regardless of the number of total individuals that could have been sampled (Hooten et al. 2016). To obtain population-level inference, one can either allow individual-level responses to arise from a shared population-level distribution (as in the data model for telemetry locations or the models accounting for repeated measures) or cluster or summarize behaviors across individuals post hoc (as in the spatial representations of movement behavior). As with any statistical analysis of observational data (as opposed to data resulting from a design-based study), a key underlying assumption is that the sample is representative of the population. In our case, we successfully modeled a significant portion of the 
population, where the population of interest was the Canada lynx that were reintroduced to the San Juan Mountains of Colorado. However, it is not always feasible to monitor the movement of such a large proportion of the population. Where possible, researchers may wish to model the probability of an individual entering the sample population, or should be aware of the assumptions in making populationlevel inference from a sample. For example, although we likely have a representative sample of individuals that were released in Colorado, our inference is conditioned on those individuals being released in the San Juan Mountains; had individuals been released at another location in the state, their movement paths would likely be different than what we observed.

This data set is one of the largest for a population of Canada lynx in the lower United States and augments the available information on movement behavior and connectivity of southern boreal lynx populations. While many of the summary statistics were focused on increasing our understanding of movement behavior (e.g. timing, duration), the spatial summary of lynx movement behavior from existing data may be particularly useful for Federal and State agencies that are required to consider lynx space use in their project planning. As with many retrospective studies, complete information regarding Canada lynx movement behavior in Colorado is unavailable. However, inference can still be obtained by using flexible modeling approaches that relax the constraints of fine-scale movement models. While fine-scale movement data are preferable when developing a new study, a large investment was made in gathering existing movement data. Despite the potential need for novel methods to analyze existing data sets, they allow for invaluable inference for movements of rare and low-density species.

Acknowledgements - Data were provided by Colorado Parks and Wildlife (CPW ACUC \#04-2000). Any use of trade, firm, or product names is for descriptive purposes only and does not imply endorsement by the U.S. Government. Data-related enquiries may be directed to Colorado Parks and Wildlife (jake.ivan@state.co.us). Funding - Funding was provided by Colorado Parks and Wildlife (1304), the National Park Service (P12AC11099), Colorado Dept of Transportation, and NSF DMS 1614392.

\section{References}

Agee, J. K. 2000. Disturbance ecology of North American boreal forests and associated northern mixed/subalpine forests. - In: Ruggiero, L. F. et al. (eds), Ecology and conservation of lynx in the United States. Univ. Press of Colorado, pp. 39-82.

Aubry, K. B. et al. 2000. Ecology of Canada lynx in southern boreal forests. - In: Ruggiero, L. F. et al. (eds), Ecology and conservation of lynx in the United States. Univ. Press of Colorado, pp. 373-396.

Avgar, T. et al. 2016. Integrated step selection analysis: bridging the gap between resource selection and animal movement. - Methods Ecol. Evol. 7: 619-630.

Bates, D. et al. 2014. lme4: linear mixed-effects models using Eigen and S4. - R package ver. 1.1-7, <http://CRAN.R-project.org/ package $=$ lme $4>$.

Bennett, A. F. 1999. Linkages in the landscape: the role of corridors and connectivity in wildlife conservation. - World Conservation Union Publications, Cambridge, UK.
Breed, G. A. et al. 2012. State-space methods for more completely capturing behavioral dynamics from animal tracks. - Ecol. Model. 235: 49-58.

Brost, B. M. et al. 2015. Animal movement constraints improve resource selection inference in the presence of telemetry error. - Ecology 96: 2590-2597.

Buderman, F. E. et al. 2016. A functional model for characterizing long-distance movement behaviour. - Methods Ecol. Evol. 7: 264-273.

Burdett, C. L. et al. 2007. Defining space use and movements of Canada lynx with global positioning system telemetry. - J. Mammal. 88: 457-467.

Buskirk, S. W. et al. 2000. Comparative ecology of lynx in North America. - In: Ruggiero, L. F. et al. (eds), Ecology and conservation of lynx in the United States. Univ. Press of Colorado, pp. 373-396.

Calabrese, J. M. and Fagan, W. F. 2004. A comparison-shopper's guide to connectivity metrics. - Front. Ecol. Environ. 2: 529-536.

Claar, J. J. et al. 2003. Wildlife linkage areas: an integrated approach for Canada lynx. - In: Proceedings of the International Conference on Ecology and Transportation. Center for Transportation and the Environment, North Carolina State Univ., Raleigh, USA, pp. 234-239.

Clevenger, A. P. et al. 2002. GIS-generated, expert-based models for identifying wildlife habitat linkages and planning mitigation passages. - Conserv. Biol. 16: 503-514.

Coulon, A. et al. 2004. Landscape connectivity influences gene flow in a roe deer population inhabiting a fragmented landscape: an individual-based approach. - Mol. Ecol. 13: 2841-2850.

Crooks, K. R. and Sanjayan, M. 2006. Connectivity conservation: maintaining connections for nature. - In: Crooks, K. R. and Sanjayan, M. (eds), Connectivity conservation, vol. 14. Cambridge Univ. Press, pp. 1-19.

Cushman, S. A. et al. 2009. Use of empirically derived sourcedestination models to map regional conservation corridors. - Conserv. Biol. 23: 368-376.

Davies, N. et al. 2013. Movement patterns of an arboreal marsupial at the edge of its range: a case study of the koala. - Mov. Ecol. 1: 8 .

del Mar Delgado, M. et al. 2009. Changes of movement patterns from early dispersal to settlement. - Behav. Ecol. Sociobiol. 64: 35-43.

Devineau, O. et al. 2010. Evaluating the Canada lynx reintroduction programme in Colorado: patterns in mortality. - J. Appl. Ecol. 47: 524-531.

Ferrari, J. R. et al. 2007. Two measures of landscape-graph connectivity: assessment across gradients in area and configuration. - Landscape Ecol. 22: 1315-1323.

Findley, J. S. and Anderson, S. 1956. Zoogeography of the montane mammals of Colorado. - J. Mammal. 37: 80-82.

Forester, J. D. et al. 2009. Accounting for animal movement in estimation of resource selection functions: sampling and data analysis. - Ecology 90: 3554-3565.

Fortin, D. et al. 2005. Wolves influence elk movements: behavior shapes a trophic cascade in Yellowstone National Park. - Ecology 86: 1320-1330.

Fuller, A. K. and Harrison, D. J. 2010. Movement paths reveal scale-dependent habitat decisions by Canada lynx. - J. Mammal. 91: 1269-1279.

Gurarie, E. et al. 2009. A novel method for identifying behavioural changes in animal movement data. - Ecol. Lett. 12: 395-408.

Hanks, E. M. 2016. ctmcmove: modeling animal movement with continuous-time discrete-space Markov chains. $-\mathrm{R}$ package ver. 1.2.3, <https://CRAN.R-project.org/package $=$ ctmcmove $>$.

Hanks, E. M. et al. 2011. Velocity-based movement modeling for individual and population level inference. - PLoS One 6: e22795. 
Hanks, E. M. et al. 2015. Continuous-time discrete-space models for animal movement. - Ann. Appl. Stat. 9: 145-165.

Hanski, I. 1999. Habitat connectivity, habitat continuity, and metapopulations in dynamic landscapes. - Oikos 87: 209-219.

Hefley, T. et al. 2017. The basis function approach for modeling autocorrelation in ecological data. - Ecology 98: 632-646.

Hijmans, R. J. 2015. geosphere: spherical trigonometry. - R package ver. $1.3-13,<$ http://CRAN.R-project.org/package $=$ geosphere $>$.

Hobbs, N. T. and Hooten, M. B. 2015. Bayesian models: a statistical primer for ecologists. - Princeton Univ. Press.

Hodges, K. E. 2000. Ecology of snowshoe hares in southern boreal and montane forests. - In: Ruggiero, L. F. et al. (eds), Ecology and conservation of lynx in the United States. Univ. Press of Colorado, pp. 163-206.

Hooten, M. et al. 2017. Animal movement: statistical models for telemetry data. - Taylor and Frances.

Hooten, M. B. et al. 2010. Agent-based inference for animal movement and selection. - J. Agric. Biol. Environ. Stat. 15: 523-538.

Hooten, M. B. et al. 2016. Hierarchical animal movement models for population-level inference. - Environmetrics 27: 322-333.

Ivan, J. S. et al. 2014. Density and demography of snowshoe hares in central Colorado. - J. Wildl. Manage. 78: 580-594.

Johnson, D. H. 1980. The comparison of usage and availability measurements for evaluating resource preference. - Ecology 61: 65-71.

Johnson, D. S. et al. 2008. Continuous-time correlated random walk model for animal telemetry data. - Ecology 89: 1208-1215.

Johnson, D. S. et al. 2011. Bayesian inference for animal space use and other movement metrics. - J. Agric. Biol. Environ. Stat. 16: 357-370.

Jonsen, I. D. et al. 2005. Robust state-space modeling of animal movement data. - Ecology 86: 2874-2880.

Jonsen, I. D. et al. 2007. Identifying leatherback turtle foraging behaviour from satellite telemetry using a switching state-space model. - Mar. Ecol. Prog. Ser. 337: 255-264.

Keyghobadi, N. et al. 2005. Genetic differentiation and gene flow among populations of the alpine butterfly, Parnassius smintheus, vary with landscape connectivity. - Mol. Ecol. 14: 1897-1909.

Killeen, J. et al. 2014. Habitat selection during ungulate dispersal and exploratory movement at broad and fine scale with implications for conservation management. - Mov. Ecol. 2: 15.

LANDFIRE 2008. LANDFIRE existing vegetation type layer. - U.S. Dept of Interior, Geological Survey, < http://landfire. cr.usgs.gov/viewer > accessed in September 2015.

Maechler, M. et al. 2013. cluster: cluster analysis basics and extensions. $-\mathrm{R}$ package ver. 1.14 .4 , for new features, see the 'Changelog' file (in the package source), <http://CRAN.Rproject.org $/$ package $=$ cluster $>$.

McClintock, B. T. et al. 2012. A general discrete-time modeling framework for animal movement using multistate random walks. - Ecol. Monogr. 82: 335-349.

McClintock, B. T. et al. 2014. Modelling animal movement using the Argos satellite telemetry location error ellipse. - Methods Ecol. Evol. 6: 266-277.

Supplementary material (Appendix ECOG-03030 at <www. ecography.org/appendix/ecog-03030>). Appendix 1-4.
Morris, D. W. 1992. Scales and costs of habitat selection in heterogeneous landscapes. - Evol. Ecol. 6: 412-432.

Morrison, C. D. et al. 2015. Space-use, movement and dispersal of sub-adult cougars in a geographically isolated population. - PeerJ 3: e1118.

Morrison, S. A. and Reynolds, M. D. 2006. Where to draw the line: integrating feasability into connectivity planning. - In: Crooks, K. R. and Sanjayan, M. (eds), Connectivity conservation, vol. 14. Cambridge Univ. Press, pp. 536-554.

Poole, K. G. 1997. Dispersal patterns of lynx in the Northwest Territories. - J. Wildl. Manage. 61: 497-505.

Rosatte, R. C. and MacInnes, C. D. 1989. Relocation of city raccoons. - In: Proceedings of the Great Plains Wildlife Damage Control Workshop 9, pp. 87-92.

Ruediger, B. et al. 2000. Canada lynx conservation assessment and strategy. - US Fish and Wildlife Publications 197.

Safranyik, L. et al. 2010. Potential for range expansion of mountain pine beetle into the boreal forest of North America. - Can. Entomol. 142: 415-442.

Sawyer, H. et al. 2005. Mule deer and pronghorn migration in western Wyoming. - Wildl. Soc. Bull. 33: 1266-1273.

Seidel, J. et al. 1998. Draft strategy for the conservation and reestablishment of lynx and wolverine in the southern Rocky Mountains. - Colorado Division of Wildlife, Fort Collins, CO, USA.

Squires, J. R. et al. 2013. Combining resource selection and movement behavior to predict corridors for Canada lynx at their southern range periphery. - Biol. Conserv. 157: 187-195.

Taylor, P. D. et al. 1993. Connectivity is a vital element of landscape structure. - Oikos 68: 571-573.

Tracey, J. A. 2006. Individual-based modeling as a tool for conserving connectivity. - In: Crooks, K. R. and Sanjayan, M. (eds), Connectivity conservation, vol. 14. Cambridge Univ. Press, pp. 343-368.

Tracey, J. A. et al. 2013. Mapping behavioral landscapes for animal movement: a finite mixture modeling approach. - Ecol. Appl. 23: 654-669.

United States Fish and Wildlife Service 2014. Endangered and threatened wildlife and plants; revised designation of critical habitat for the contiguous United States distinct population segment of the Canada lynx and revised distinct population segment boundary; final rule. - Federal Register 79: 54782-54846.

Vandel, J. M. et al. 2006. Reintroduction of the lynx into the Vosges mountain massif: from animal survival and movements to population development. - Biol. Conserv. 131: 370-385.

Walpole, A. A. et al. 2012. Functional connectivity of lynx at their southern range periphery in Ontario, Canada. - Landscape Ecol. 27: 761-773.

Wear, B. J. et al. 2005. Factors affecting settling, survival, and viability of black bears reintroduced to Felsenthal National Wildlife Refuge, Arkansas. - Wildl. Soc. Bull. 33: 1363-1374.

Wolff, J. O. 1980. The role of habitat patchiness in the population dynamics of snowshoe hares. - Ecol. Monogr. 50: 111-130.

Wood, S. N. and Augustin, N. H. 2002. GAMs with integrated model selection using penalized regression splines and applications to environmental modelling. - Ecol. Model. 157: 157-177. 